\title{
Comparison of Rapid Immunochromatographic Kits with ELISA for Detection of Dengue in Acute Febrile Cases in a Tertiary Health Care Centre
}

\author{
Ritu Agarwal $^{1 *}$, Gunjan Pandey ${ }^{1}$ and Niraj Kumar Yadav ${ }^{2}$
}

${ }^{1}$ Department of Microbiology, ${ }^{2}$ Department of Preventive and Social Medicine, G S Medical College \& Hospital (Chaudhary Charan Singh University), Pilkhuwa, Uttar Pradesh, India

*Corresponding author

\section{A B S T R A C T}

Keywords

Dengue, RDT (Rapid Diagnostic Kit),

ELISA

Article Info

Accepted:

12 September 2018

Available Online:

10 October 2018
Dengue fever is increasing in incidence each year and with each monsoon season looms a fear of morbidity and mortality by dengue fever Measures by Government to prevent its spread have not been successful to a very large extent and probably require a more intensive approach towards the etiological causes. Until then early diagnosis and treatment remain the key to escape the damage caused by it. To compare Rapid immunochromatography based kits and ELISA which has been the mainstay of diagnosis of dengue. Serum samples from suspected dengue cases were subjected to both RDT and ELISA for detection of N1S antigen, IgG and IgM antibodies. Out of 285 suspected cases, 65 cases were found to be positive for NS1 by both RDT and ELISA whereas IgM and IgG antibody detection was more by ELISA. Diagnosis of dengue by NS1 antigen by RDT is at par with ELISA whereas antibody detection is better by ELISA.

\section{Introduction}

Dengue, a viral fever spread by Aedes mosquito, has become a recurrent feature in northern India. It causes extensive morbidity and also loss of life in severe cases. In most of the cases it is a self-limiting disease but a few cases progress to various complications like DHF, DSS because of which early diagnosis and treatment of all cases is a must.

In India, 1,11,880 cases of dengue were reported in 2016 with 227 deaths and 28,702 cases were reported till July 2017 with 46 deaths (NVBDCP, 2010).

The number of cases reported each year has been increasing with 40571, 99913 and 1,11880 cases reported in 2014, 2015, and 2016 respectively. This trend is alarming because it reflects that containment measures at all level be it vector breeding and transmission are all failing (Singh, 2006).

Dengue is caused by single stranded positive sense RNA flavivirus belonging to family 
Flaviviridae and has 4 serotypes - DENV $1,2,3,4$. The strains exhibit cross reactivity but can be distinguished by serological and molecular markers (Rice et al., 1986).

Signs and symptoms of classical dengue fever are headache, muscle, bone and joint pain, nausea, vomiting, retroorbital pain, swollen glands and rash. DHF symptoms are similar to dengue fever with severe and continuous pain in abdomen, bleeding from the nose, mouth and gums or skin bruising, black stools, excessive thirst, pale, cold skin, restlessness, or sleepiness. DSS symptoms are similar to DHF with weak rapid pulse, narrow pulse pressure (less than $20 \mathrm{~mm} \mathrm{Hg}$ ), cold, clammy skin and restlessness.

The main methods of diagnosis of dengue involve RTPCR, virus isolation and characterization, Rapid immunochromatographic (ICT) tests and ELISA based techniques (National Guidelines for Clinical Management of Dengue Fever, 2014). RTPCR and virus isolation though very sensitive but are expensive, require time and elaborate set up which is a limiting factor in suburban and rural settings of India (Kong et al., 2006). ICT and ELISA are relatively rapid in their comparison and easy to perform (Mitra et al., 2016). Both the techniques detect the presence of NS1 (Young et al., 2000) (a 50 $\mathrm{kd}$ glycoprotein secreted by virus infected cells) and dengue specific $\operatorname{IgM}$ and $\operatorname{IgG}$ antibodies.

NS1antigen has been reported and detected from day 1 to day 14 of onset of symptoms viz. fever, bodyache, malaise. IgM antibody takes 5-10 days to appear in cases of primary dengue fever and 4-5 days in case of secondary infection. IgG antibody appears after 14 days and persists for life in primary dengue infection whereas in secondary dengue it appears within 1-2 days after the onset of symptoms.
Since ICT and ELISA make use of these antibody levels for diagnosis of dengue and these tests are most commonly used for quick diagnosis of dengue, we decided to undertake the present study in which we compared ICT based RDT which give qualitative estimate of NS1, IgM and IgG vs. ELISA which gives quantitative estimate of NS1, IgG and IgM titres. Comparison of both techniques would help us in knowing the efficacy, sensitivity and specificity of both techniques and their shortcomings and their utility in resource limited settings (Dussart et al., 2008; Pal Subhamoy et al., 2014).

\section{Materials and Methods}

The present study was carried out in a tertiary care hospital in western UP from July 2016 to June 2017. Patients of all age groups presenting to OPD with sign and symptoms of acute dengue fever viz., headache, myalgia were included in the study.

All the cases were of less than 5 days duration barring a few cases which came after 5 days and were not included in the study.

Out of 340 patients presenting to OPD with sign and symptoms of dengue fever, serum samples from 285 cases were subjected to both ICT and ELISA NS1, IgM and IgG for comparison whereas remaining 55 cases were subjected only to RDT due to non-availability of ELISA kits.

After drawing the blood samples under aseptic conditions, the serum was utilized for performing the above tests. The RDT was from J. Mitra and company and gives NS1, $\operatorname{IgM}$ and $\operatorname{IgG}$ results based on lateral flow technique. Capture ELISA for IgM and IgG and direct sandwich ELISA for NS1 was performed as per instruction booklet by the manufacturer. The results were analysed on MedCalc statistical software. 


\section{Results and Discussion}

The male female ratio for the suspected patients in our study was 124:161. Maximum number of cases for male patients presented in the age group of 11-20 yrs closely followed by 21-30 yrs age group. For the female patients, maximum number of females presented in the age group of 21-30 years followed by 31-40 years. Overall maximum number of patients presented in the 21-30 years age group i.e. 75 out of 285 patients.

An important and interesting result of our study was that out of 285 cases whose serum samples were subjected to both RDT and ELISA, 65 cases were detected to be NS1 positive by RDT and exactly these same cases were also shown positive by ELISA. This revelation reiterates the fact that RDT are equally good as ELISA for detection of NS1. This also reflects that for rapid diagnosis of early dengue infection, RDT is a good, reliable and inexpensive diagnostic technique which can prevent the occurrence of severe complications like DHF and DSS by rapid diagnosis.

However detection of $\operatorname{IgM}$ and $\operatorname{IgG}$ antibodies by RDT and ELISA showed marked variation in the study. All the 65 NS1 positive cases were subjected to IgM and IgG detection by ELISA whereas as RDT has inbuilt window for showing $\operatorname{IgM}$ and $\operatorname{IgG}$ results along with NS1.

RDT showed cases to be $35 \operatorname{IgM}$ positive whereas IgM ELISA was positive for 225 cases. The 225 cases included all the 65 positive NS1 cases.

Similarly IgG, which appears during 7-9 days of infection and persists for life was shown to be positive in 25 cases in RDT whereas IgG ELISA was positive for 205 cases. Table 1 shows various statistical values where IgM, $\operatorname{IgG}$ by both the techniques have been put to statistical comparison.

\section{Age distribution of suspected dengue cases}

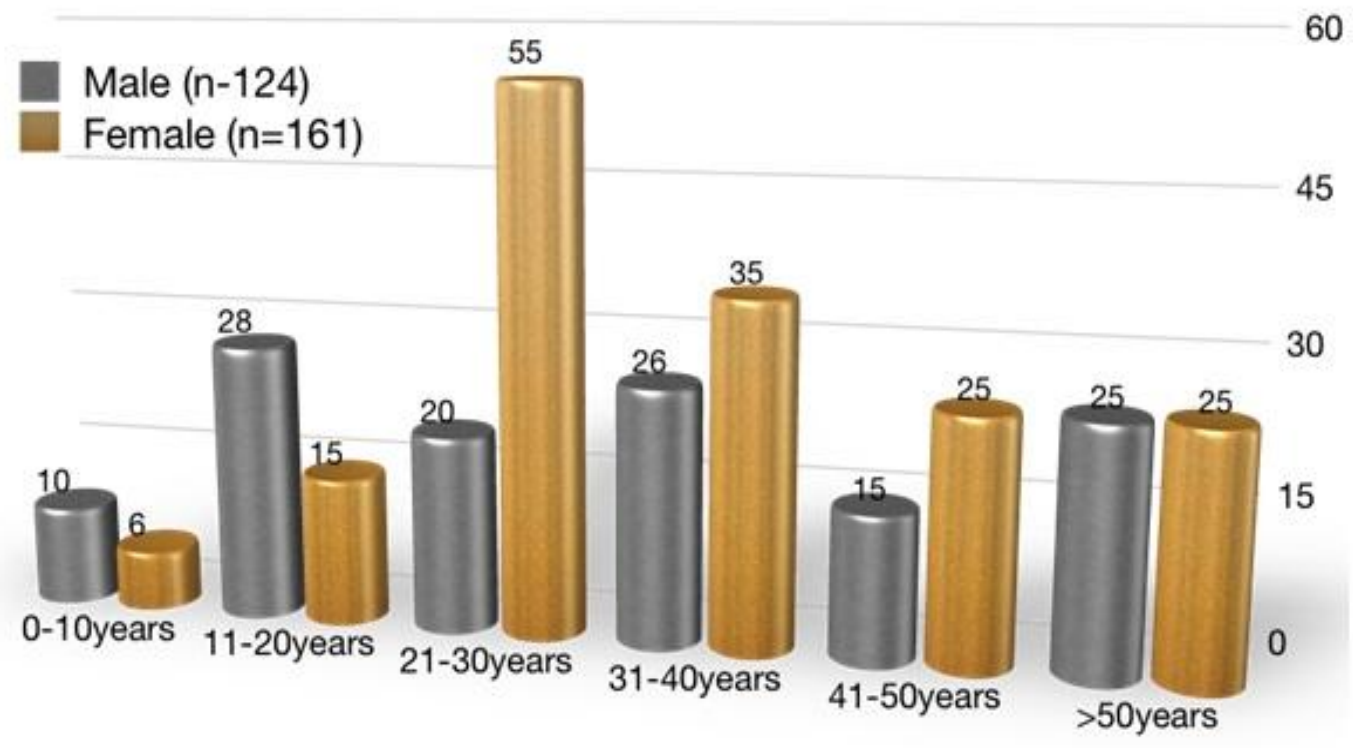


Table.1 Validity and predictive values of rapid ICT vs ELISA for IgM and IgG antibody detection

\begin{tabular}{|l|c|c|c|c|}
\hline \multicolumn{1}{|c|}{ Parameter } & \multicolumn{2}{|c|}{ IgM: Rapid ICT vs ELISA } & \multicolumn{2}{c|}{ IgG: Rapid ICT vs ELISA } \\
\hline Value & $\mathbf{9 5 \%}$ Confidence intervals & $\begin{array}{c}\text { Value } \\
\text { 95\% Confidence intervals }\end{array}$ \\
\hline Sensitivity & $86.54 \%$ & $81.78 \%$ to $90.44 \%$ & $89.13 \%$ & $84.37 \%$ to $92.84 \%$ \\
\hline $\begin{array}{l}\text { Specificity } \\
\text { Positive } \\
\text { Predictive Value }\end{array}$ & $78.56 \%$ & $79.35 \%$ to $87.22 \%$ & $79.75 \%$ & $75.44 \%$ to $83.60 \%$ \\
\hline $\begin{array}{l}\text { Negative } \\
\text { Predictive Value }\end{array}$ & $89.71 \%$ & $74.75 \%$ to $82.61 \%$ & $71.93 \%$ & $67.70 \%$ to $75.80 \%$ \\
\hline
\end{tabular}

The above results strongly show that while antigen detection is equally sensitive by both RDT and ELISA, antibody detection is definitely far more sensitive by ELISA.

Our study showed that number of female patients (161) was more than male patients (124) which are in contrast to most of the previous studies like (Chakravarti and Kumaria, 2005). It could be due to regional differences or a random finding. Also the age group in which maximum number of males presented corroborated the study by (Gore, 2005) in which also maximum number of males presented in the similar age group. The maximum number of female patients in age group 21-30 years is similar to the study (Desh et al., 2011).

Same number of NS1 positive cases being detected by RDT and ELISA $(p \leq .5)$ is a finding similar to the finding by (Stephen $e t$ al., 2014) which also shows that same cases being detected by RDT and ELISA.

Since NS1 detection was exactly similar by both the methods, we compared RDT for IgM vs. IgM capture ELISA for statistical purposes and it showed sensitivity of $86.54 \%$, specificity $83.56 \%$, PPV $78.15 \%$ and NPV $89.71 \%$. Similarly, we compared RDT for IgG vs. IgG capture ELISA and found it to have sensitivity $89.13 \%$, specificity $79.75 \%$, PPV $71.93 \%$ and NPV 92.65\%. In a similar study by (Mahesh Reddy et al., 2016) sensitivity for IgM Rapid vs. ELISA is $92.57 \%$ while specificity is $98.53 \%$.

Our study strongly reflects that in resource limited settings where tests like ELISA cannot be put up, RDT NS1 detection is equally good as early diagnosis and it is the key to prevention of serious complications of dengue like DHF, DSS. ELISA is fairly superior in detection of $\operatorname{IgM}$ and $\operatorname{IgG}$ antibodies and classification of cases in to primary and secondary cases.

\section{References}

Chakravarti, A., and R. Kumaria. 2005. Eco Epidemiological Analysis of Dengue Infection during an Outbreak of Dengue Fever, India. Virol. J., 2. http://dx.doi.org/10.1186/ 1743-422X232.

Dash PK, Sharma S, Srivastava A, Santhosh SR, Parida MM, Neeraja M, et al., Emergence of dengue virus type 4 (genotype I) in India. Epidemiol Infect 2011; 139(6): 857-61. DOI: 10.1017/S0950268810001706.

Dussart P, Petit L, Labeau B, Bremand L, Leduc A, Moua D, et al., Evaluation of Two New Commercial Tests for the Diagnosis of Acute Dengue Virus Infection Using NS1 Antigen Detection in Human Serum. PLoSNegl Trop Dis 
2008; 2(8): e280. DOI:10.1371/ journal.pntd.0000280

Gore MM. Need for constant monitoring of dengue infection. Indian $\mathrm{J}$ Med Res 2005; 121(1): 9-12.

Kong, Y. Y., C. H. Thay, T. C. Tin, and S. Devi. 2006. Rapid detection, serotyping and quantitation of dengue viruses by TaqMan real-time one-step RT-PCR. J. Virol. Methods 138:123-130. https:// doi.org/10.1016/j.jviromet.2006.08.003

Mahesh Reddy, R., Kavita Sahai, Ajay Malik, S. Shoba and Anurag Khera. Comparative Analysis of Rapid Testing and ELISA for NS1 Antigen and IgM IN Acute Dengue Infection. International J. of Current Micobiology and Applied Sciences (2016) 5(10):931937. http://dx.doi.org/10.20546/ ijcmas.2016.510.100

Mitra, Shubhanker, et al., 2016. "Comparative Evaluation of Validity and Cost-Benefit Analysis of Rapid Diagnostic Test (RDT) Kits in Diagnosis of Dengue Infection Using Composite Reference Criteria: A CrossSectional Study from South India." J. Vector Borne Dis., 53(1): 30-36. PMID: 27004576.

NVBDCP (National Vector Borne Disease Control Programme). Dengue Cases and
Deaths in the Country since 2010. http://www.nvbdcp.gov.in/dencd.html.

Pal Subhamoy, et al., 2014. Evaluation of Dengue NS1 Antigen Rapid Tests and ELISA Kits Using Clinical Samples. PloS one, 9(11): e113411. https://doi.org/10.1371/journal.pone.011 3411

Rice, C. M., E. G. Strauss, and J. H. Strauss. 1986. Structure of the flavivirus genome, p. 279-326. InS. Schlesinger and M. J. Schlesinger (ed.), The Togaviridae and Flaviviridae. Plenum, New York, NY.

Singh B. Dengue outbreak in 2006: failure of public health system? Indian J. Community Med. 2007; 32: 99-100.

Stephen S, Charles MP, Anitharaj V, Deepa C, Umadevi S. Early dengue diagnosis by non-structural protein 1 antigen detection: Rapid immune chromotography versus the enzymelinked immunosorbent assay kits. Indian J Pathol Microbiol 2014; 57(1):81-84. DOI: $10.4103 / 0377-4929.130905$

Young, PR., Hilditch PA, Bletchly C. 2000. An antigen capture enzyme-linked immunosorbent assay reveals high levels of the dengue virus protein NSlin the sera of infected patients. J.Clin.Microbiol.38:10531057.

\section{How to cite this article:}

Ritu Agarwal, Gunjan Pandey and Niraj Kumar Yadav. 2018. Comparison of Rapid Immunochromatographic Kits with ELISA for Detection of Dengue in Acute Febrile Cases in a Tertiary Health Care Centre. Int.J.Curr.Microbiol.App.Sci. 7(10): 1646-1650. doi: https://doi.org/10.20546/ijcmas.2018.710.187 